\title{
Análise comparativa entre arranjos de aquisição de dados geoelétricos 2D em área de ocorrência de manganês alojada em sequencia metassedimentar
}

\author{
César Augusto Moreira ${ }^{1}$; Erica Mariano ${ }^{2}$; Nicolas Peixoto da Silveira Campos ${ }^{3}$; Alice Marques Pereira ${ }^{4}$; Samuel Siqueira \\ Reis ${ }^{5}$; Walter Malagutti Filho ${ }^{6}$; Carolina Del Roveri ${ }^{7}$ \\ 1, 2, 3, 4, 5, 6 Instituto de Geociências e Ciências Exatas. Universidade Estadual Paulista - UNESP - Rio Claro (SP) \\ ${ }^{7}$ Instituto de Ciencia e Tecnologia (ICT), Universidade Federal de Alfenas - UNIFAL - Poços de Caldas (MG)
}

Copyright 2014, SBGf - Sociedade Brasileira de Geofísica

Este texto foi preparado para a apresentação no VI Simpósio Brasileiro de Geofísica Porto Alegre, 14 a 16 de outubro de 2014. Seu conteúdo foi revisado pelo Comitê Técnico do VI SimBGf, mas não necessariamente representa a opiniño da SBGf ou Tecnico do VI SimBG , mas ná necessariamente representa a opinia da si propósitos comerciais sem prévia autorização da SBGf.

\section{Resumo}

O estudo e aperfeiçoamento de procedimentos técnicos de investigação do ambiente geológico visa a otimização de recursos financeiros e a aumento da probabilidade de descoberta de novos depósitos, no âmbito de estudos de prospecção e pesquisa mineral. Este trabalho realiza uma análise comparativa entre arranjos de aquisição de dados geoelétricos 2D, em levantamento realizado sobre uma ocorrência de manganês residual encaixado em sequência metassedimentar com alto ângulo de mergulho, localizada na região de Natércia, sul de Minas Gerais. A seção obtida para o arranjo Dipolo-dipolo realça a provável posição do nível aquífero livre (contato saprolito/rocha), mas não permite o reconhecimento de zonas mineralizadas ou intervalos com veios de quartzo verticais, descritos em superfície. Os resultados obtidos para os arranjos Schlumberger e Wenner foram correlacionáveis as estruturas e feições geológicas descritas em superfície e possivelmente refletem com fidelidade o contexto geológico em profundidade.

\section{Introdução}

O setor mineral compreende as etapas de pesquisa, mineração e transformação, consiste na base para diversas cadeiras produtivas. Sua participação atual no produto interno bruto (PIB) nacional é de $4,2 \%$ e representa cerca de $20 \%$ das exportações brasileiras, por meio de uma cadeia produtiva que gera 1 milhão de empregos diretos, equivalente a $8 \%$ dos empregos industriais. Os insumos minerais que atualmente destacam o Brasil no cenário internacional são o nióbio, ferro, bauxita, manganês e cobre, além de ouro e rochas ornamentais (MME, 2010).

De suma importância para manutenção e crescimento econômico brasileiro, o setor mineral é dependente de pesquisas geológicas básicas para ampliação de jazidas conhecidas e em processo de lavra, além da descoberta de novas ocorrências e depósitos minerais.

Este conjunto de atividades é denominado pesquisa mineral, que reúne uma série de etapas de planejamento e estratégias baseadas no insumo mineral de interesse, que variam desde o modelo genético e forma de ocorrência no ambiente geológico, métodos e procedimentos de investigação, como geofísica e geoquímica, até condicionantes econômicos, como demanda, valor de mercado e projeções futuras (Maranhão, 1985; Moon et al. 2007).

Devido ao custo relativamente baixo e possibilidade de ampla cobertura em diferentes condições de terreno, os métodos geofísicos constituem uma importante ferramenta em pesquisa mineral. Enquanto a aerogeofísica é empregada em trabalhos regionais, métodos elétricos e eletromagnéticos podem ser utilizados em estudos de detalhes, sobre alvos selecionados por estudos geofísicos ou geoquímicos prévios.

Em conjunto com a magnetometria, tais métodos são bastante adequados ao estudo de depósitos de sulfetos e óxidos disseminados (Moon et al., 2007; Telford et al., 2004). Diversos trabalhos descrevem as vantagens e desvantagens, benefícios e limitações do uso destes métodos em pesquisa mineral (Alis, 1990; Irvine \& Smith, 1990; White et al., 2001; Moreira \& Ilha, 2011; Moreira et al., 2012; Moreira et al, 2013).

Este trabalho realiza um estudo comparativo em arranjos de aquisição de dados geoelétricos, efetivado sobre uma ocorrência de manganês residual alojada em sequência metassedimentar de alto ângulo, descrita na região de Natércia, sul de Minas Gerais.

\section{Metodologia/ Problema Investigado}

O município de Natércia está localizado ao sul-sudoeste do Estado de Minas Gerais (Figura 1), próximo ao município de Heliodora e Pouso Alegre.

Natércia está distante aproximadamente $300 \mathrm{~km}$ de Rio Claro, 260 km de São Paulo e 370 km de Belo Horizonte, com 4658 habitantes, distribuídos em uma área de 189 $\mathrm{km}^{2}$, com economia relacionada ao setor de serviços, agricultura e indústria (IBGE, 2012).

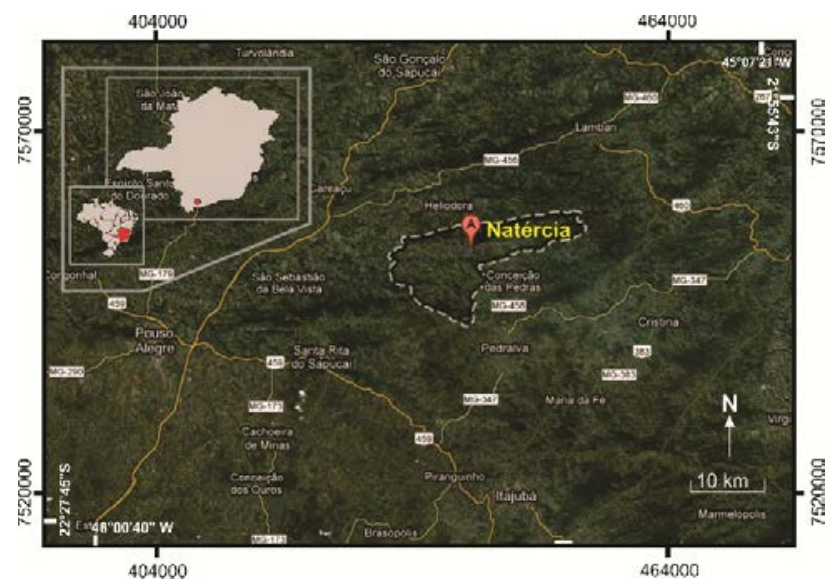

Figura 1 - Área de estudos 
A região de Natércia está situada na Faixa de Dobramentos Alto Rio Grande, localizada ao sul do Cráton do São Francisco, com formato de trapézio com aproximadamente $350 \mathrm{~km}$ de extensão e direção geral WSW-ENE, desde a Bacia do Paraná a oeste, até a região entre Paranaíba- Juiz de Fora (CPRM, 1988).

Esta faixa de dobramentos é caracterizada por evolução policíclica, com indícios de vários eventos tectonometamórficos que afetaram tanto as sequências supracrustais quanto o embasamento arqueano. Sua provável idade é Proterozóica Inferior, sendo que o seu maior pico metamórfico ocorreu durante o Ciclo Uruçuano (CPRM, 1988). As principais estruturas dessa faixa foram consolidadas no Ciclo Jequié (2,5 G.a). O processo de colisão continental favoreceu a formação de bacia marginal, com sedimentação terrígena fina inicial, intercalada por vulcanoclásticas, derrames e intrusões máficas e ultramáficas. Esse conjunto foi submetido a um cisalhamento dúctil de baixo ângulo, além de um metamorfismo de fácies xisto verde a anfibolito no Ciclo Uruçuano, sucedida por dobramentos amplos associados a zonas de cisalhamento transpressivas e metamorfismo na fácies xisto verde (CPRM, 1988).
Os principais litotipos da área pertencem ao Complexo Silvianópolis. As principais unidades geológicas de interesse para o presente estudo estão listadas abaixo, sendo descritas no relatório do PLGB (Projeto de Levantamentos Geológicos Básicos do Brasil), escala 1:50.000, Folha Heliodora (CPRM, 1988)

A ocorrência mineral faz parte de um conjunto de diversos alvos que ocorrem isoladamente nas regiões de Careaçu, Heliodora e Natércia, sul de Minas Gerais. As ocorrências mais conhecidas estão relacionadas principalmente a corpos de gondito intercalados em quartzitos muscovíticos e muscovita xistos pertencentes ao Complexo Lambari/Silvianópolis, cuja gênese é atribuída a oxidação superficial de espessartita e precipitação de óxidos de ferro e manganês (Figura 2).

$\mathrm{O}$ alvo de estudo consiste em impregnações de manganês secundário contidos em solo de alteração de granada muscovita xisto, caracterizada por uma associação de pirolusita, wad, psilomelana, goethita, hematita e magnetita, com textura terrosa a puvirolenta A área é fortemente estruturada, com foliação do xisto bastante pronunciada, contada por veios de quarzto, com mergulho médio próximo de $80^{\circ}$ para NE. (Figura 3).

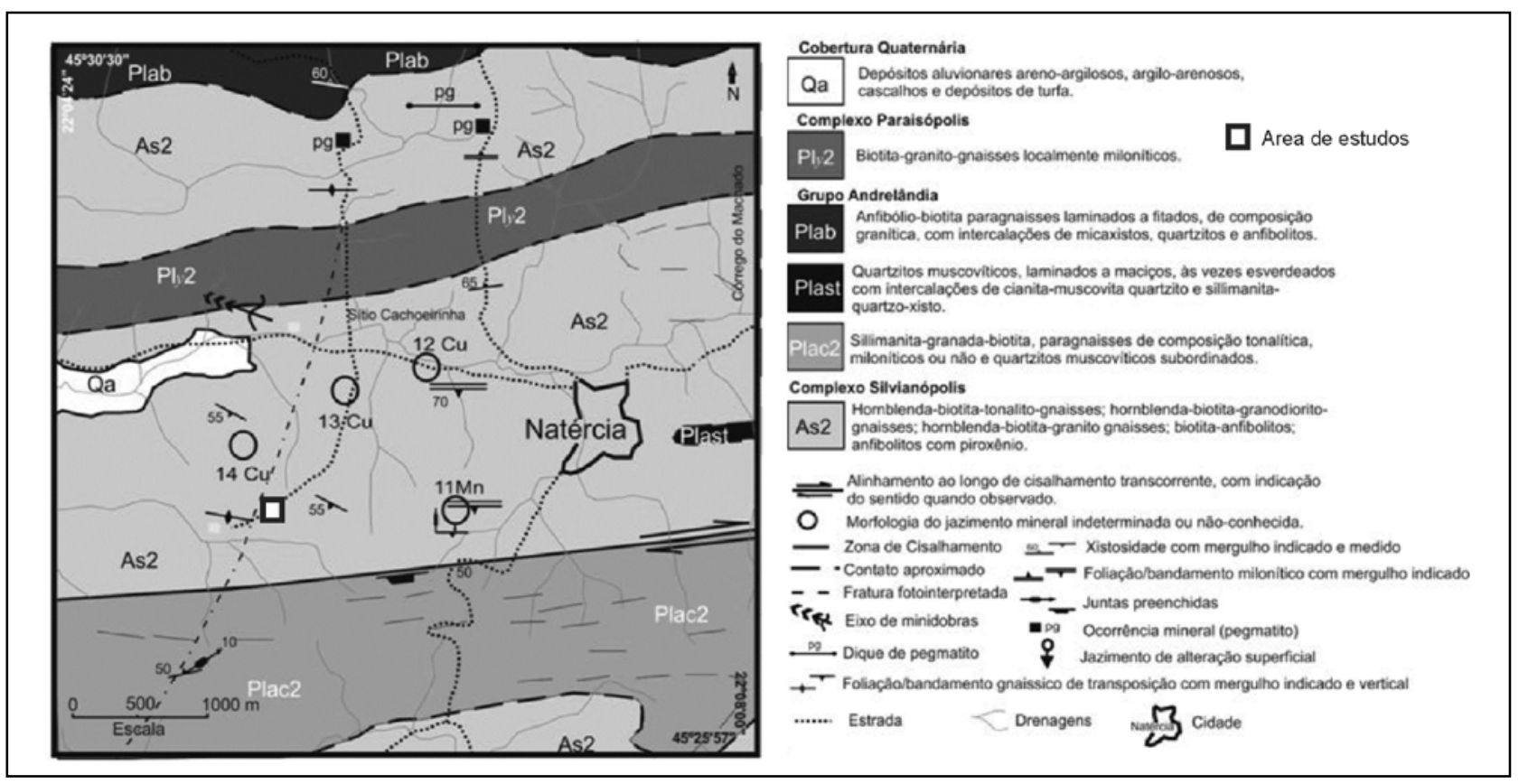

Figura 1 - Mapa geológico da área de estudos (Adaptado de CPRM, 1988).

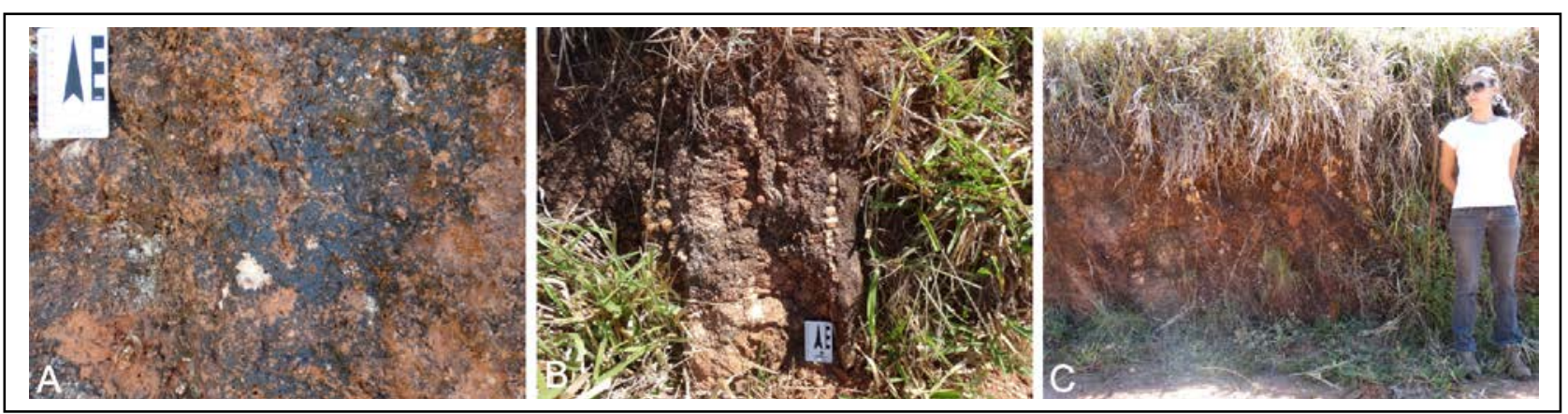

Figura 2 - A) Impregnações de manganês em solo. B) Veio de quartzo vertical. C) Foliação (xistosidade) subvertical. 


\section{Resultados}

Os dados foram adquiridos por meio de uma linha de caminhamento elétrico com total de $104 \mathrm{~m}$, com espaçamento entre eletrodos de $2 \mathrm{~m}$, disposta de forma a cruzar perpendicularmente a estruturação das rochas da área. Foram utilizados eletrodos não polarizáveis, preenchidos por uma solução supersaturada a base de sulfato de cobre $\left(\mathrm{CuSO}_{4}\right)$.

As leituras de resistividade elétrica e cargabilidade foram realizadas de forma concomitante por meio resistivímetro Terrameter LS, a partir de um sistema multicabo de aquisição pré-programada e automática de dados.

Foram definidos os seguintes parâmetros de aquisição: corrente máxima de $100 \mathrm{~mA}$, tempo de leitura de $1000 \mathrm{~ms}$, janela única de leitura de 100ms posicionada após $100 \mathrm{~ms}$ do corte de corrente.

Após a programação do equipamento e montagem da linha em campo, foram aplicados três arranjos de aquisição de dados: dipolo-dipolo, Schlumberger e Wenner, numa tentativa de avaliar a sensibilidade e resolução individual a presença de mineralizações manganíferas e a foliação da rocha encaixante.

O Dipolo-dipolo é um arranjo tradicionalmente empregado na aquisição de dados elétricos $2 \mathrm{D}$, devido a versatilidade em campo e a possibilidade de leituras de potencial para diversas profundidades a partir do mesmo ponto de injeção de corrente elétrica, algo que proporciona uma grande produtividade em termos de tempo e quantidade de medidas (Telford et al., 2004). É caracterizado pelo uso de pares de eletrodos de corrente dispostos de forma alinhada, referenciados a extremidade inicial da linha, separados de pares de eletrodos de potencial também alinhados, distanciados de forma crescente para medidas em maiores profundidades. A principal desvantagem deste arranjo é a queda na relação sinal/ruído com o aumento da distancia entre pares de corrente e potencial (maiores profundidades) e a maior probabilidade de distorção de campo elétrico em áreas com forte estruturação das rochas.

Os arranjos Wenner e Schlumberger são tradicionalmente empregados por meio da técnica de sondagem elétrica vertical, embora sejam aplicáveis em aquisições 2D (Milson \& Eriksen, 2011). Consistem no uso de um conjunto básico de quatro eletrodos alinhados, referenciados a um ponto central, onde os eletrodos de potencial são posicionados próximo ao centro e os eletrodos de corrente posicionados nas extremidades do arranjo. A movimentação deste conjunto básico ao longo da linha de aquisição de dados possibilita investigações laterais, ao passo que leituras em maiores profundidades requer o aumento do espaçamento entre eletrodos.

O arranjo Wenner é caracterizado por aberturas entre eletrodos com espaçamentos constantes e equivalentes, enquanto que o arranjo Schlumberger consiste em aberturas constantes mas sempre maiores entre corrente e potencial (sempre menor ou igual a $1 / 5$ da abertura de corrente) (Orellana, 1972). O primeiro é recomendado para terrenos com controle estratigráfico ou disposição de camadas horizontais ou sub-horizontais, ao passo que o arranjo Schlumberger possibilita investigações em profundidades comparativamente maiores, além da menor sensibilidade aos horizontes superficiais. Ambos permitem um ganho substancial em termos de relação sinal/ruído devido ao envio de corrente nas extremidades e leituras do centro, embora tenham a desvantagem de aquisições mais demoradas em relação ao arranjo Dipolo-dipolo e uma maior logística de campo para equipamentos simples.

\section{Discussão e Conclusões}

Os dados foram processados no programa Res2Dinv, desenvolvido pela Geotomo softwares e apresentados em termos de modelo de inversão para análise comparativa. As seções foram agrupadas quanto ao parâmetro físico analisado (Figuras 3 e 4).

As seções de resistividade apresentam valores que variam de $51 \Omega$.m a $7236 \Omega$.m. Em termos comparativos, as seções para os arranjos Schlumberger e Wenner apresentam padrões equivalentes quanto a áreas de ocorrências de alta e baixa resistividade.

Ambas apresentam faixas de alta resistividade horizontalizadas e próximas a superfície, que possivelmente correspondem ao horizonte de solo/saprolito local, truncadas por uma faixa central de menor resistividade, em cuja superfície é representada por uma extensa ocorrência impregnações de óxidos de manganês e ferro no solo (Figura 2A).

Há ainda uma zona de transição brusca e verticalizada de valores de baixa para alta resistividade na porção central, que possivelmente reflete um intervalo com veios de quartzo com mergulho próximo a $90^{\circ}$ descritos na superfície (Figura 2B).

Existe ainda uma faixa de baixa resistividade a partir de $64 \mathrm{~m}$ no sentido final das seções, posicionada abaixo de $5 \mathrm{~m}$ de profundidade, bastante pronunciada na seção do arranjo Schlumberger, mas identificável na seção do arranjo Wenner. A falta de continuidade sentido a superfície e a ausência de indícios de impregnações de óxidos nas exposições em campo para esta região em superfície, impedem identificações diretas. Contudo, em semelhança ao padrão da zona central das seções e sua associação com impregnações de óxidos em superfície, a referida faixa pode representar uma zona de acumulação de óxidos de manganês e ferro não aflorante.

O modelo de inversão para o arranjo Dipolo-dipolo é caracterizado por elevados valores de resistividade, descontínuos somente numa faixa horizontal contínuo, com profundidade média de $7 \mathrm{~m}$ a $10 \mathrm{~m}$, além de uma zona de baixa resistividade central abaixo de $20 \mathrm{~m}$. Esta faixa contínua pode representar o contato saprolito/rocha e um eventual nível aquífero livre, sendo esta a única relação plausível com estruturas geológicas presentes na área de estudos. Associações entre estruturas como veios de quarto, xistosidade ou acumulações de óxidos descritos em superfície não são passíveis de identificação nesta seção.

As seções de cargabilidade são caracterizadas por baixos valores, entre $0,01 \mathrm{mV} / \mathrm{V}$ e $3,94 \mathrm{mV} / \mathrm{V}$ Os dados relativos as medidas de cargabilidade não foram relacionáveis as seções de resistividade, nem a quaisquer estruturas geológicas descritas em superfície. Este fato pode ser creditado a existência de materiais de baixa polarizabilidade e a possibilidade da transmissão 
de corrente elétrica de baixa intensidade durante a realização dos ensaios.

A seção para o arranjo Dipolo-dipolo aparentemente realçou o nível aquífero livre, pouco pronunciado nos demais modelos. Contudo, estruturas geológicas descritas em superfície não foram passíveis de continuidade para maiores profundidades nesta seção. Desta forma, o produto de aplicação do arranjo Dipolodipolo simplesmente não refletiu o contexto geológico local, possivelmente devido à baixa relação sinal/ruído incrementada com o aumento da profundidade, além de distorções de campo e potencial elétrico ocasionadas pela foliação de alto ângulo e contato vertical entre materiais com resistividade bastante distinta.

Em contrapartida, a semelhança entre as seções para os arranjos Schlumberger e Wenner em termos de resistividade, são atribuíveis aos princípios físicos de posicionamento em superfície do dispositivo de transmissão e recepção de dados. A possibilidade de transmissão de corrente nas extremidades do arranjo e leituras de potencial no centro potencializam a sensibilidade das leituras de potencial elétrico, mesmo num contexto geológico complexo, caracterizado por foliação de alto ângulo e constantes bruscos de resistividade elétrica entre zonas de acumulação de óxidos e faixas com veios de quarto. A caracterização destas zonas, respectivamente de baixa e alta resistividade em superfície, e sua continuidade em profundidade, indicam a fidelidade dos resultados relativos a ambos os arranjos ao contexto geológico local.

\section{Agradecimentos}

Este trabalho foi realizado com recursos auferidos junto a FAPESP (Fundação de Amparo à Pesquisa do Estado de São Paulo), por meio do projeto de pesquisa intitulado "Prospecção geofísica em ocorrência de manganês supergênico na região de Natércia, Sul de Minas Gerais", processo n²013/09219-5.

\section{Referências}

Allis, R. Geophysical anomalies over epithermal systems. Journal of Geochemical Exploration, v. 36, p. $339-374$, 1990.

CPRM - Companhia de Pesquisa de Recursos Minerais. Programa de Levantamentos Geológicos Básicos do Brasil; carta geológica, carta metalogenética/previsionalEscala 1:50.000 (Folha SF.23-Y-B-II-2 Heliodora). Estado de Minas Gerais. Brasília, DNPM/CPRM, 1988.

IBGE - Instituto Brasileiro de Geografia e Estatística. ecidades. Disponível em www.ibge.gov.br. Acesso em 04/12/2012.

Irvine, R. J., Smith, M. J. Geophysical exploration for epithermal gold deposits. Journal of Geochemical Exploration, v. 36, p 375-412, 1990.

Maranhão, R.J.L. 1985, Introdução a Pesquisa Mineral. Banco do Nordeste do Brasil, Fortaleza, $2^{\circ} \mathrm{ed}$., 796 pp.
Milson J., Eriksen A., 2011, Field Geophysics. John Wiley \& Sons, Oxford, 297pp.

MME - Ministério das Minas e Energia - Brasil. 2010. Plano Nacional de Mineração 2030 (PMN - 2030). Brasília, MME, 178p.

Moreira, C. A. \& Ilha, L. M. Prospecção geofísica em ocorrência de cobre localizada na bacia sedimentar do Camaquã (RS). Revista da Escola de Minas, Ouro Preto, v. $64, n^{0} 3$, p. 309-315, 2011.

Moreira, C. A.; Lopes, S. M.; Schweig, C.; Seixas, A. R. Geoelectrical prospection of disseminated sulfide mineral occurrences in Camaquã sedimentary basin, Rio Grande Sul State, Brazil. Revista Brasileira de Geofísica, v. 30, n², p. 169-179, 2012.

Moreira, C. A.; Borges, R. M,; Vieira, G. M. L.; Malagutti Filho, W.; Montanheiro, M. A. F. Geological and geophysical data integration for delimitation of mineralized areas in a supergene manganese deposits. Geofísica Internacional, v. 53, n², p. 199-210, 2014.

Moon, C. J.; Whateley, M. E. G.; Evans, A. 2006, M. Introduction to Mineral Exploration. 2o ed., Backwell Publishing, Oxford, 499 pp.

Orellana, E. 1972, Prospeccion Geoeletrica en corriente continua. $2^{\circ}$ Ed., Madrid, Espanha, 545 pp.

Telford, W. M.; Geldart, L. P.; Sheriff, R. E. 2004. Applied Geophysics. Cambridge University Press, New York, $2^{\circ}$ ed., 774 pp.

White S. R.M.S. Collins R. Denne R. Hee R. Brown P. A new survey design for $3 \mathrm{D}$ IP inversion modelling at copper hill. Exploration Geophysics, vol. 32, p.152 - 155, 2001. 
"NATERCKA","Schlumberger_1"
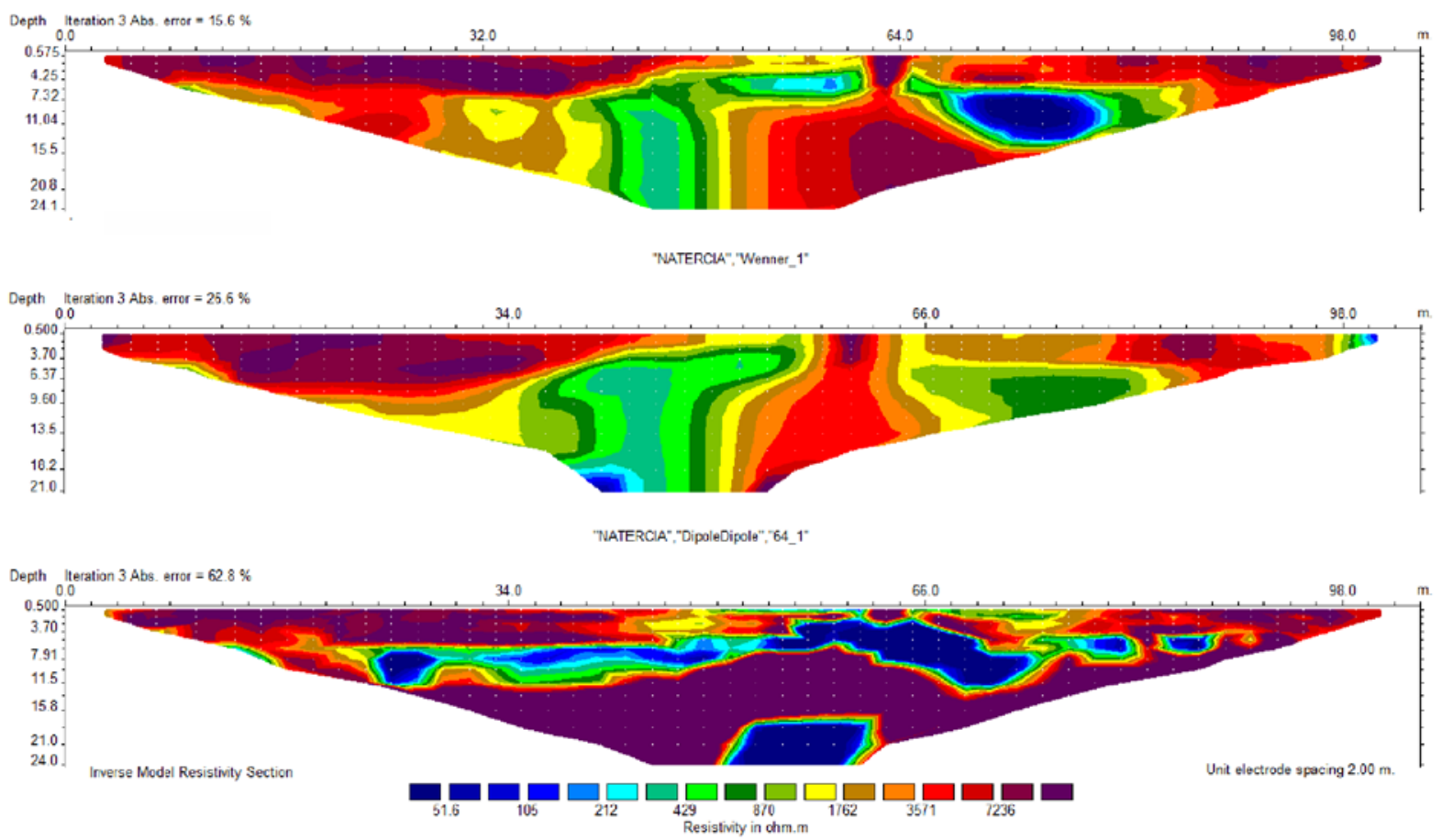

Figura 3 - Modelos de inversão em termos de resistividade elétrica
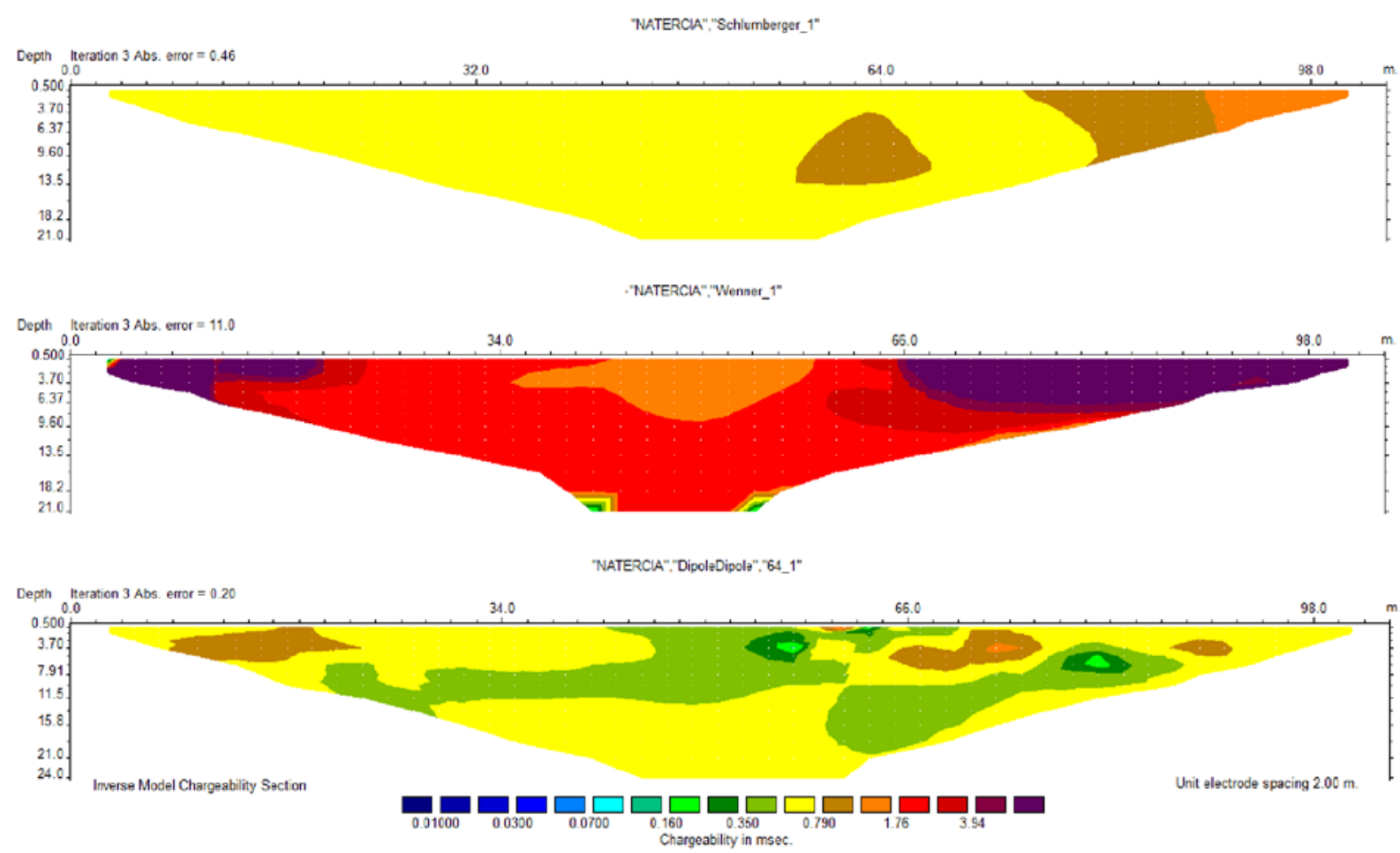

Figura 4 - Modelos de inversão em termos de cargabilidade 